less than $0 \cdot 1 \%$ of the organisms originally present on the test surface in the case of skin." Although a moist mucosal surface should transfer a higher proportion of organisms to the sponge, the subsequent liberation of these organisms is necessarily inefficient in any contact-transfer procedure.

If its serious quantitative limitations are borne in mind this procedure should prove a very convenient aid in ecological studies of accessible mucosal surfaces. Certainly this important area of investigation at present lags far behind the flourishing field of skin ecology.

SydNey SELWYN

Department of Bacteriology,

London SW 1

Oates, J K, Selwyn, S, and Breach, M R, British Journal of Venereal Diseases, 1971, 47, 289. Selwyn, S, and Ellis, H, British Medical fournal, 1972 1,136 .

\section{Compulsory fluoridation}

SIR,-Because almost all of the personal views put forward in your article about priorities (25 December, p 1548) are plainly sensible and excellent I consider it to be a pity that you allowed one of them to be weakened by a comment derisory of those with whom you clearly disagree. Personally I accept the evidence of the beneficial effects of fluoride on dental health, but, scrannel pipe or not, I oppose the compulsory fluoridation of drinking water supplies and I think that there are acceptable alternatives.

Surely our duty is to advise and not to compel? It is simple enough to follow the advice of our dental colleagues and to recommend the consumption of an appropriate dose of fluoride for so long as is necessaryinexpensive supplies are easily obtained from pharmacies. If we can convince people to believe sufficiently in the benefits of fluoride it would be comparatively inexpensive for the Department of Health and Social Security to provide fluoride tablets and, as with contraceptives, the cost of supply would be far less than the cost of failing to supply them in terms of expense to the National Health Service. What price must be paid to add fluoride to drinking water supplies where this is indicated when most of it would be wasted and how does the cost compare with that of for example, making fluoride tablets freely available to those who need them ? Compulsory fluoridation of drinking water supplies seems to suffer from many disadvantages apart from the obvious one of compelling people, in what is said to be a democratic society, to take steps to look after their own health. The dose would be imprecise: some would consume very little water and others (I recall a former patient with diabetes insipidus) a very great deal. Why is it sensible to add fluoride to the water in which one bathes (or have I overlooked evidence of percutaneous absorption?) or with which one washes one's car, waters one's garden, or supplies to edentate people or to birds and animals ?

You very properly point out the advantages of fluoride and you equally properly state that we need public co-operation and a much more informed population. The remedy for dental health is simple: people should be encouraged to look after their own health and just as they should avoid cigarettes and corpulence so too ought they to ensure that they, and more especially their children, consume an appropriate quantity of fluoride. It is easy to give advice to a most receptive audience at antenatal clinics and simple to recommend fluoride as well as iron. I submit that the artificial, compulsory fluoridation of drinking water supplies is not the obvious answer to the need for fluoride, that there are strong and reasonable arguments against it, that there is a satisfactory alternative, and that you are being less than fair to those from whom you differ.

Let us have a scrannel pipe for compulsion and a diapason for information and encouragement towards self-help.

R N PALMeR

Sawbridgeworth, Herts

\section{Femoral neck fractures}

SIR,-In the report of their regional survey of femoral neck fractures (18 December, $p$ 1496) $\mathrm{Mr}$ S C Gallannaugh and his colleagues remind us again of the heavy demand for hospital beds made by patients with this condition. The fact that the majority of cases occur in the over-75 age group must prompt great concern in face of the expected increase in numbers in that age group over the next 10-15 years.

The report is slightly less helpful than it might have been, however, for providing the incidence rate of fracture of the femoral neck which might be expected in the population. The authors show that they are aware that hospital discharge rates do not necessarily equate with true incidence rates even for a condition with a very high, if not total, rate of hospitalisation like fracture of the neck of the femur. There is, as they say, the inflationary effect of inter-hospital transfers, but whereas they dismiss this as small and occurring mainly in the elderly, they give no actual estimate of the effect. In the Trent Region in 1975, as the accompanying table shows, approximately one in five spells of hospital stay for fracture of the neck of the femur were the result of transfers from other NHS hospitals. As the table also shows, approximately $5 \%$ of admissions were by prior arrangement after a waiting time. These are patients who are admitted for revision of the internal fixation originally applied to the joint during the acute episode. It is arguable whether such cases should still be labelled as fracture of the neck of the femur, but the practice may exist in the SW Thames Region as in Trent.

Another possible source of inaccuracy is the positioning in the list of diagnoses on form HMR1, used for data collection in Hospital Activity Analysis, of fracture of the neck of the femur. If it was the main cause of admission to hospital it should occupy the first, or primary, diagnostic position on the form. Experience in this region has shown that this convention

Fracture of neck of femur (ICD 820): number of discharges by source of admission, Trent Region, 1975 (Source: Hospital Activity Analysis)

\begin{tabular}{|c|c|c|}
\hline \multirow{2}{*}{ Source of admission } & \multicolumn{2}{|c|}{ Fracture of neck of femur } \\
\hline & $\begin{array}{c}\text { Primary } \\
\text { diagnosis }\end{array}$ & $\begin{array}{c}\text { Non-primary } \\
\text { diagnosis }\end{array}$ \\
\hline $\begin{array}{l}\text { Waiting list } \ldots \\
\text { Booked or planned } \\
\text { Immediate } \ldots \\
\text { Transferred from other } \\
\text { NHS hospitals }\end{array}$ & $\begin{array}{r}64 \\
64 \\
2237 \\
551\end{array}$ & $\begin{array}{r}9 \\
28 \\
199 \\
106\end{array}$ \\
\hline Total & 2916 & 342 \\
\hline
\end{tabular}

is not always followed. As the table shows, the diagnosis appeared in a secondary position in about one in 10 cases. In many of these the primary position is occupied by "bronchopneumonia," a condition which developed postoperatively in hospital and which in some cases resulted in the patient's death. Reference to the report of the Hospital In-patient Enquiry (HIPE) for $1971^{1}$ shows that in the SW Metropolitan Hospital Region, the predecessor of the SW Thames Health Region, 269 beds were occupied daily by patients with fracture of the neck of the femur, a similar number to that estimated by $\mathrm{Mr}$ Gallannaugh and his colleagues. The Hospital In-patient Enquiry uses only the primary diagnosis on the HMR1 forms, which suggests that, unless NHS reorganisation radically altered the number of hospital beds available in that region in 1974, the authors have also used only the primary diagnosis.

Moreover the 1971 HIPE report shows that the discharge rate for fracture of the neck of the femur in the SW Metropolitan Region (8.6 per 10000 population) was the highest among all the regions (lowest 3.9 ; average $6 \cdot 4)$. Regional populations are not sufficiently different in structure to explain these disparities, nor is it likely that there are great differences in the proportions of patients who fracture a femur who are admitted to hospital. It is possible, therefore, that transfer between hospitals occurs on quite a large scale in that region.

One other cautionary word is called for before using the data presented in the article for comparison with incidence rates from other sources, whether true incidence rates or those based on hospital discharges. The incidence rates per 1000 population quoted in table I of the article are based on the population aged 45 years and over and not the total population. This has to be deduced from the text.

B T Williams

Trent Regional Health Authority, Sheffield

Department of Health and Social Security, Report of the Hospital In-patient Enquiry for 1971. London,
$\mathrm{HMSO}, 1973$.

SIR,-Mr S C Gallannaugh and his colleagues, in drawing attention to the problems presented to the Health Service by patients with fractures of the femoral neck (18 December, p 1496), give age-specific "incidence" rates for this injury. In order to avoid confusion it is worth emphasising that their figures are in fact hospital admission rates and not incidence rates. As they point out, their admission rates are higher than the widely accepted incidence rates found by Knowelden et al. ${ }^{1}$ When applied to the population of England and Wales in 1971 the rates of $\mathrm{Mr}$ Gallannaugh and his colleagues give a total of 28700 hospital admissions among people aged 65 or more, while those of Knowelden et al give a total of 21500 cases of fracture of the neck of the femur. This difference is explained by the fact that, in hospital discharge statistics, the same person with the same injury is counted more than once when he is transferred between hospitals or readmitted. For fractures of the neck of the femur transfers and waiting-list admissions constitute $25 \%$ of the total admissions, ${ }^{2}$ which is sufficient to account for most of the difference. Furthermore, the incidence rates found by Knowelden et al were confirmed in a report by the Oxford 